\title{
PKM Pendampingan Penguasaan Bahasa Inggris pada Reading Comprehension Menggunakan Metode Skimming dan Scanning di BPK (Badan Pembinaan Khusus) MTs Nurul Jadid Probolinggo
}

\author{
Abdullah Al Anis, ${ }^{1}$ Anis Zahro ZU, ${ }^{2}$ Jamilatunnisa' Bashori, ${ }^{3}$ \\ Rusnasari, ${ }^{4}$ Izzatul Mauliya, ${ }^{5}$ Lita Amini ${ }^{6}$ \\ Universitas Nurul Jadid, Probolinggo \\ abdullah81alanisfauzi@gmail.com, aniszahrozu@gmail.com², \\ nisajamila60@gmail.com³ ,rusnasari123@gmail.com ${ }^{4}$, izzamaulia99@gmail.com ${ }^{5}$, \\ lyta.amini99@gmail.com ${ }^{6}$
}

Submission: 22/08/2021 Received: $13 / 11 / 2021 \quad$ Published: $31 / 12 / 2021$

\section{Keywords: \\ Reading \\ Comprehension, \\ Skimming, \\ Scanning.}

Katakunci:

Reading

Comprehension,

Skimming,

Scanning.

\begin{abstract}
The ability to read someone in English is a skill that not most people can do. This shows that this ability requires practice, seriousness, persistence, and talent to have the ability and even reading skills in the field of English. Through this Community Service, the which became the point of the point was mentoring students at BPK MTs Nurul Jadid in fostering the Skimming and Scanning method can improve reading skills comprehensively which pushes forward on previous abilities. So the purpose of this Study to to ease the students in learning reading skill for achieving the Goal of study in learning English especially in readng skill. BPK (Special Development Agency) which one of the programs is language skills, in this realm the author will unify planning, In methodology researcher used experimntal research pres-test post-test design to students or students in BPK institutions one class only by scanning and skimming way used to facilitate a reader's ability to read a text. The Result is the scanning and skimming way can affect significantly cause students got score 75 by using scanning and skimming way than students did not use the scanning and skimming way got score 60 in passing grade 80. Thus, this method is affected to Reading skill students in BPK Insitution.
\end{abstract}

\begin{abstract}
Abstrak. Kemampuan membaca seseorang dalam bahasa Inggris adalah keterampilan yang tidak bisa dilakukan kebanyakan orang. Hal ini menunjukkan bahwa kemampuan ini membutuhkan latihan, kesungguhan, ketekunan, dan bakat untuk memiliki kemampuan bahkan keterampilan membaca dalam bidang bahasa Inggris. Melalui Pengabdian kepada Masyarakat ini yang menjadi poin penting adalah pendampingan siswa di BPK MTs Nurul Jadid dalam membina metode Skimming dan Scanning dapat meningkatkan kemampuan membaca secara komprehensif yang mendorong maju pada kemampuan sebelumnya. Jadi tujuan
\end{abstract}




\begin{abstract}
dari penelitian ini adalah untuk memudahkan siswa dalam belajar keterampilan membaca untuk mencapai tujuan belajar dalam pembelajaran bahasa Inggris khususnya dalam keterampilan membaca. BPK (Badan Pembinaan Khusus) yang salah satu programnya adalah keterampilan berbahasa, dalam ranah ini penulis akan menyatukan perencanaan, Dalam metodologi peneliti menggunakan penelitian eksperimen desain pres-test post-test kepada mahasiswa atau mahasiswa di lembaga BPK satu kelas saja dengan cara scan dan cara skimming digunakan untuk mempermudah kemampuan pembaca dalam membaca suatu teks. Hasilnya cara scanning dan skimming dapat berpengaruh secara signifikan menyebabkan siswa mendapat nilai 75 dengan menggunakan cara scanning dan skimming dibandingkan siswa yang tidak menggunakan cara scanning dan skimming mendapat nilai 60 secara sepintas kelas 80 . Dengan demikian, metode ini berpengaruh terhadap keterampilan membaca siswa di Lembaga BPK.
\end{abstract}

\title{
1 Pendahuluan
}

Westernisasi telah mewarnai kemajuan dan perkembangan negaranegara berkembang di dunia, tidak terkecuali negara kita Indonesia. Corak kehidupan masyarakat Eropa kerap sekali dijadikan acuan hidup oleh mudamudi jaman sekarang. Dari pola hidup, cara berpakaian, dan bahasa, masayarakat Indonesia tidak sedikit yang menjiplak bangsa berkulit putih itu. Namun, dari beberapa pengaruh yang tersebar, dampak dari ketidak pahaman masyarakat malah mengakibatkan mereka salah jalur dalam meniru. Budaya kehidupan bangsa barat tidaklah salah, bahkan dengan banyaknya para pengikut hal tersebut bisa menjadi sesuatu yang lumrah. Namun di berbagai tempat kebudayaan semacam itu masih dipandang sebagai sebuah keasingan bagi orang-orang yang kurang mengenal budaya tersebut. Ketidak singkronan inilah yang sering menimbulkan kesalah pahaman antar rakyat yang memiliki perbedaan pendapat. Dari hal tersebut, maka sangat pokok untuk generasi muda memahami dan mengerti Bahasa Inggris yang dalam kiprahnya sebagai bahasa internasional dapat membantu para muda-mudi agar tidak mudah terpengaruh hal buruk dan dapat bersaing di kancah internasional. Bahasa Inggris merupakan bahasa nomer satu dan internasional dunia,hampir seluruh negara di dunia mempelajari dan menggunakan bahasa Inggris. Oleh karena itu di zaman modern ini Bahasa Inggris menjadi hal wajib untuk dilatih dan dipelajari sejak dini (Hoed, 2014). Dengan begitu, seharusnya setiap lapisan masarakat dapat membuka pikiran 
yang luas dan mengambil jalan tengah agar tidak terjadi kesalahpahaman yang berkelanjutan sehingga menimbulkan pertikaian. Salah satu usaha pemerintah dalam menangani hal tersebut ialah dengan memajukan kualitas pendidikan di Indonesia, agar generasi mudannya dapat secara sistematis membuka pikiran terhadap hal-hal baru namun tidak dengan cepat terpengaruh hal-hal yang buruk.

Selain pendidikannya yang harus maksimal, SDM yang belajar juga harus mengimbangi pendidikan yang ditempanya, maka setiap sekolah di Indonesia memiliki sistem yang berbeda-beda untuk mencapai maksimal pembelajaran untuk siswa siswinya. Hal tersebut melatarbelakangi Mts Nurul Jadid Paiton Probolinggo memberlakukan sistem pembelajaran di sekolah tersebut dengan membagi siswa-siswinya dalam dua bagian kelas yakni kelas intensif dan kelas reguler, untuk memasuki kelas intensif para siswa harus mengikuti beberapa tes. Siswa dan siswi yang masuk dalam kelas intensif memiliki kesempatan belajar yang lebih intensif dan banyak dalam mata pelajaran yang ditekuninya. Kelas intensif disini disebut sebagai BPK (Badan Pembinaan Khusus). Dengan adanya asrama khusus bagi siswa-siswi kelas intensif, yang dalam hal ini disebut sebagai BPK (Badan Pembinaan Khusus) tentunya hal ini memberikan pengalaman tersendiri bagi mereka, misalnya persaingan dalam tingkat akademik sudah pasti sangat tinggi melihat siswa-siswi yang berada dalam kelas pembinaan khusus dapat dikatakan memiliki tingkat pemahaman terhadap pelajaran lebih tinggi karena berhasil bersaing dengan banyaknya siswa-siswi yang mendaftar dalam tes masuk.

Badan Pembinaan Khusus (BPK) adalah sebuah lembaga yang berdiri dibawah naungan MTs Nurul Jadid. Yang didirikan dalam rangka membina siswa/siswi yang unggul serta memiliki potensi untuk memperdalam kajian kitab salaf serta kebahasaan (Arab/ Inggris) sehingga dapat menghasilkan output yang berkualitas. Siswa-siswi anggota BPK diasramakan khusus dengan pembinaan intensif untuk mengembangkan kemampuan keagamaan dan kebahasaannya.Dalam kesehariannya, siswa/siswi BPK diwajibkan berbahasa inggris dan bahasa arab, baik di asrama maupun di luar asrama. Sehingga mampu berkomunikasi dengan lancar, aktif dan mandiri.

Dari segi penguasaan berbahasa Inggris peserta didik BPK memiliki kemampuan di atas standar untuk siswi tingkat SLTP dalam pencapaiannya. Selain aktif berbahasa Inggris mereka pula aktif mengerjakan tugas-tugas 
yang berkaitan dengan Bahasa Inggris dalam 4 kemampuan (reading, writing, speaking, dan listening). Dalam pembelajaran reading comprehension, kebanyakan peserta didik memahami kalimat dari kata per kata, akibatnya mereka sering bermasalah dalam di atu kata sebelum mereka menyelesaikan satu paragraf, hal inilah yang mengahambat proses pembelajaran (Dina, 2016). Oleh karena itu adanya metode-metode dalam reading akan mempermudah peserta didik dalam memahami suatu bacaan. Dalam hal ini metode skimming and scanning dirasa signifikan untuk dikuasai peserta didik untuk memahami dengan cepat dan tepat suatu bacaan. Skimming adalah suatu tehnik mencari kata atau kalimat yang merupakan intisari dari sebuah teks, sementara scanning adalah strategi untuk menemuka sebuah informasi yang dicari dengan cepat dalam suatu teks (Harmer, 2001). Menurut Arundel dalam Reading and Study Skill Lab (1999) skimming adalah tehnik mencari cepat sebuah intisari atau idea pokok dalam suatu tulisan. Selanjutnya ada beberapa step dalam mengaplikasikan skimming pada teks: (1) Membaca judul, (2) Membaca pendahuluan di paragraf pertama, (3) Membaca Paragraf satu secara keseluruhan, (4) Membaca setiap kalimat pertama di setiap paragraf, (5) Lihat keseluruhan teks, lalu tandai infomasi penting yang berhubungan denga ide pokok, (6) Baca kesimpulan secara keseluruhan.

Berdasarkan penjelasan di atas, dapat disimpulkan bahwa skimming dan scanning adalah metode yang tepat untuk diaplikasi pada peserta didik BPK (Badan Pembinaan Khusus) supaya membantu mereka menguasai kemampuan reading comprehension.

\section{Metode}

Metode yang digunakan dalam pendampingan ini adalah pendekatan kuantitatif dengan desain experimental disertai model pretest-posttest. Creswell (2003) menyatakan pendekatan kuantitatif adalah metode penelitian dengan menjelaskan sebuah permasalahan dengan pengumpulan data dan menganalisisnya menggunakan metode matematika. Sasaran populasinya yakni siswi BPK (Badan Pembinaan Khusus) Mts Nurul Jadid tahun pelajaran 2020-2021 yang berjumlah 200 siswi. Penulis memilih kelas VII dan kelas VIII BPK yang kesemuanya terdapat 49 siswi sebagai kelas experimen, karena dari segi keaktifan dalam belajar bahasa Inggris kelas tersebut adalah yang paling intensif. 
Dalam pendampingan belajar ini, penulis menggunakan percobaan pre dan post-test. Siswi diminta untuk membaca sebuah teks dalam waktu 90 detik dan menemukan poin-poin dengan menjawab soal yang tersedia setelah membaca. Lalu pada pertemuan selanjutnya, siswi diberi treatment (pembelajaran) terkait skimming dan scanning untuk menambah wawasan mereka. Setelah pemberian treatment, siwi mengerjakan pos-test yang telah disediakan dengan kriteria teks yang diberikan satu tingkat lebih sulit dari teks pre-test dalam segi bahasa.

Prosedur pengumpulan data untuk kelas experimen sebagai berikut: 1) melaksanakan pre-test kepada siswi sebelum pembelajaran lebih lanjut terkait skimming dan scanning, 2) pembelajaran atau pemahaman materi skimming dan scanning, 3) memberikan post-test kepada siswi setelah pemberian materi.

Pada analisis data, jawaban siswi pada pre-test dan pos-test diperoleh dengan cara sebagai berikut: 1) membuat kunci jawaban (jawaban yang benar) untuk soal pre-test dan post-test, 2) mengklasifikasikan nilai yang didapat menjadi empat tinkatan, $100-90=$ Excellent, $89-80=$ Good, 79 $60=\mathrm{Bad},<60=$ Very Bad, 3) menentukan passing grade (KKM) untuk penilaian 4) mengkalkulasikan nilai yang diperoleh, mengambil rata-rata nilai (mean).

Dalam penentuan nilai pre-test dan post-test, penulis menggunakan scoring sistem sebagai berikut:
- Jawaban benar
$: 25$
- Jumlah pertanyaan : 5
- Nilai total : $5 \times 20=100$
- Nilai jawaban siswi : jawaban benar $\times 10$ 


\begin{tabular}{|l|l|}
\hline Tingkatan Nilai & Kategori \\
\hline $40-59$ & Very bad \\
\hline $60-79$ & Bad \\
\hline $80-99$ & Good \\
\hline 100 & Excellent \\
\hline Passing grade (KKM) & $>80$ \\
\hline
\end{tabular}

\section{Hasil}

Adapun hasil yang telah dicapai dalam pendampingan Reading Comprehension dengan metode skimming dan scanning dapat meningkatkan daya tarik siswa dalam mempelajari reading comprehension. Sehingga, pengimplementasian reading dengan metode skimming dan scanning bisa meningkatkan skill reading siswa secara lebih signifikan, khususnya dalam menentukan ide pokok sebuah teks.

Selain itu, data hasil penilaian pre-test dan post-test yang telah dilakukan juga menunjukkan kefektifan metode skimming dan scanning untuk meningkatkan kecekatan siswi dalam menara idea pokok sebuah bacaan. Dari hasil mean (nilai rata-rata) yang di dapat, mean post test yakni 75 lebih tinggi dari mean pre-test yang 60 .

Hasil pre-test

\begin{tabular}{|l|c|c|}
\hline Nilai & Frekuensi & Mean \\
\hline $40-59$ & 14 & \\
\hline $60-79$ & 21 & \\
\hline $80-99$ & 12 & 60 \\
\hline 100 & 2 & \\
\hline
\end{tabular}


Hasil post-test

\begin{tabular}{|l|c|c|}
\hline Nilai & Frekuensi & Mean \\
\hline $40-59$ & 3 & \\
\hline $60-79$ & 16 & \\
\hline $80-99$ & 22 & 73 \\
\hline 100 & 8 & \\
\hline
\end{tabular}

Oleh karena itu, penggunaan metode skimming dan scanning dalam skill reding dipandang perlu dilakukan, karena dapat mempermudah siswa dalam mengidentifikasi teks. Metode yang telah disebutkan juga mempunyai keuntungan tersendiri. Seperti, siswa akan lebih fokus pada setiap bagian teks yang perlu diidentifikasi. Sehingga, secara tidak langsung dengan metode skimming dan scanning siswa dapat menggunakan waktu dengan lebih efektif. Selain itu, metode skimming dan scanning diharapkan dapat mempermudah siswa dalam mempelajari reading comprehension.

\section{Kesimpulan}

Setelah melakukan ekperiment, ditemukan bahwa nilai rata antara pre-tes (60) dan post-test (5) sangat berbeda. Hampir seluruh siswi BPK tidak mencapai passing grade / KKM pada pre-test, dari 49 orang yang berpartisipasi dalam pendampingan ini, hanya 14 siswi yang mencapai KKM pada pre-test. Setelah dilakukan pembelajaran dan pendampingan penguasaan metode skimming dan scanning, jumlah siswi yang mencapai nilai KKM bertambah, dari 14 orang menjadi 30 orang. Melihat dari hasil postest yang telah dilakukan, ada peningkatatan yang lebih sifnifikan, yakni nilai rata-rata yang lebih tinggi daripada hasil pre-test. Hal tersebut menunjukkan bahwa pemahaman siswi pada metode skimming dan scanning sangat lah membantu mereka untuk menyelesaikan teks reading yang diberikan.

Dari hasil penemuan dan diskusi di atas, dapat disimpulkan metode skimming dan scanning sangatlah efektif untuk penguasaan materi reading 
comprehension. Siswi dapat dengan mudah menemukan poin-poin yang dicari dalam sebuah teks, saat mereka memahami bagaimana metodenya. Pendampingan dengan metode skimming and scanning dianggap effektif.

\section{Referensi}

Ali Azmi, d. (2020). The Effect of Skimming and Scanning Strategies on. Atlantis Press, 465.

Best, J. W. (1981). Research In Education 4th Edition. New Jersey: PrenticeHall, Inc.

Crewswell, J. (2003). Research design: Qualitative, quantitative, and mixed method approaches. Los Angeles, CA: Sage Publications, Inc.

Elliot, J. (1991). Action Research for Educational Change: Developing Tacher and Teaching. London: Open University Press.

Harmer, J. (2001). The Practice of English Language Teaching. Third Edition. London.

Hasan, I. (2002). Pokok-Pokok Materi Statistika 1 (Statistik Deskriptif) Edisi Kedua. Jakarta: PT Bumi Aksara.

Maxwell, J. M. (1972). Skimming and Scanning Improvement: The Needs,. Journal of Reading Behavior, 5.

McMillan, J. (1992). Education Research: Fundamentals of Consumers. New York: Harper Collins Publisher.

Sari, D. M. (2018). The Use of Skimming and Scanning Technique to Improve Reading Comprehension Achievement of Junior Highschool Students. Jurnal Edukasi, 59-68.

Sudjana. (Metode Statistika). 2002. Bandung: Tarsito.

Yusuf, Q. (2017). Skimming and Scanning Techniques to Assist EFL Students in . Indonesia Research Journal in Education, 43-57. 